\title{
Polio in Italy
}

\section{Bernardino Fantini (*)}

$\left(^{*}\right) \quad$ Institute for the History of Medicine and Health, University of Geneva.

Bernardino.fantini@unige.ch

Dynamis

[0211-9536] 2012; 32 (2): 329-359
Fecha de recepción: 23 de enero de 2012

Fecha de aceptación: 5 de marzo de 2012

SUMMARY: 1.-Introduction. 2.-The epidemiology of polio in Italy. 3.-The social and scientific reactions to the polio epidemics. 4.-The 1958 epidemics. 5.-The different actors. 6.-The vaccination campaign and the elimination of the disease. 7.-Changing attitudes in patients and the public. 8.-The origins of patient's associations. 9.-The post-epidemic problems. The post-polio syndrome. 10.-Concluding remarks.

ABSTRACT: The history of polio in Italy is relatively short because the particular social and demographic history of the country has actually compressed the most dramatic history of the polio epidemic into only 40 years, from the first severe epidemic just before World War II to the early 1980 s, when the epidemic vanished thanks to an effective and country-wide vaccination campaign. The epidemic, however, had a formidable impact on medicine, public health, social attitudes and culture. An analysis of this case study can illustrate the impact of an epidemic of a severe disease on individual and collective life, and at the same time the efficacy of public health measures against it, and the importance of the social structure, state and private, in coping with the consequences of the epidemics. In this period, the attitude towards the handicapped changed from stigma and isolation to social integration, thanks especially to the changes in health legislation, social action and the initiatives of the patient' associations.

KEY WORDS: poliomyelitis, Italy, vaccination campaigns, human rights, patient's associations, economy of health.

PALABRAS CLAVE: poliomielitis, Italia, campañas de vacunación, derechos humanos, asociaciones de pacientes, economía de la salud.

\section{Introduction}

The history of polio pandemics in the western world covers a relatively short period of time, just under seven decades, from the turn of the twentieth century to the beginning of the 1980s. Although the disease continues to 
be a serious problem in underdeveloped countries, it has disappeared in the developed world. Total eradication might be achieved in the near future and recent epidemics have never reached the level of severity and social impact that they had in the first six decades of the twentieth century. In a rapid succession of events the explosion of the disease was balanced out by an impressive series of new international activities and technological advances, such as the rapid introduction of effective vaccines and new therapeutic and rehabilitation techniques.

This is particularly true for Italy, because the unique social and demographic history of the country after its unification in 1861 actually compressed the most dramatic history of the polio epidemic into only 40 years, from the first severe epidemic just before World War II to the second part of the 1970s, when the epidemic vanished thanks to an effective and country-wide vaccination campaign. The epidemic however had a formidable impact on medicine, public health, social attitudes and culture. An analysis of this case study can illustrate the impact of an epidemic of a severe disease on the individual and collective life, and at the same time the efficacy of public health measures against it, and the importance of social structures, both state and private, in coping with the relevant consequences of the epidemics, which were particularly severe.

Each country had a different epidemic history, varying according to sanitary level of its population, and a specific way of reacting to the disease and its consequences, depending on the particular structure of the public and private institutions of care and treatment, and the nature of social dynamics, such as the existence of associations and public opinion movements. Italy is particularly interesting from this point of view, because at the time of the epidemic it was a relatively young state, with an economy quickly passing from a traditional agricultural structure to a modern industrial one. The nation experienced a long period of dictatorship (1923-1943), and an extremely rapid economic development after World War II; the so-called miracolo italiano (the Italian miracle). The weakness of the Italian state structure, and at the same time the strong solidarity existing among the population, characterizes in a specific way the impact of polio epidemics and the prise en charge of its consequences.

As for the other developed countries, the emergence of poliomyelitis, a relatively rare disease, already present in Antiquity and well described in the clinical literature of the nineteenth century, was perceived as a 
paradox ${ }^{1}$ by the medical and public health community, especially in the 1950s. With the introduction of antibiotics, insecticides and new drugs, medicine appeared able to eliminate infectious diseases as public health problems and the attention of public health authorities switched to chronic and constitutional diseases.

\section{The epidemiology of polio in Italy}

The disease was already known in Italy at the beginning of the nineteenth century. Giovanni Battista Monteggia (1762-1815) in the 2nd edition of his Surgical Institutions (Monteggia 1813), in the chapter on Paralysis and Atrophy, reported a precise clinical description of several cases of infant paralysis:

«a certain kind of paralysis limited to one or the other of the lower extremities

(...) It occurs in children who are nursing, or not much later; it begins with two or three days of fever, after which one of these extremities is found quite paralyzed, immobile, flabby, hanging down, and no movement is made when the sole of the foot is tickled $»^{2}$.

The epidemiological impact was hard to grasp, as the disease was limited to a small number of mysterious paralytic diseases. Until the end of the nineteenth century polio was considered a disease of infants and young children, a paediatric disease. The reports on clinical cases were published in paediatric journals, and most specialists were paediatricians.

The real impact of the disease was hidden, as a large part of the infections were silent, invisible or symptomless, and able to produce a permanent immunity. Most infected people had no symptoms, while many others experienced only a brief febrile episode, which was usually disregarded. Only at the end of the nineteenth century did the Italian medical journals start to mention cases of paralysis in young adults ${ }^{3}$ and to describe the changing

1. Shell, Marc. Polio and its aftermath. The paralysis of culture. Cambridge, Mass.: Harvard University Press; 2005.

2. English translation from Paul, John. A History of poliomyelitis. New Haven: Yale University Press; 1971, p. 28.

3. Medea, Eugenio. Beitrag zur Kenntnis der poliomyelitis anterior subacuta adultorum. Monatsschrift für Psychiatrie und Neurologie. 1908; 23:17. 
physiognomy of the disease, and especially its specific epidemiological distribution and the relevant difference in clinical signs of the severe cases, with important nervous lesions and weakness of the muscles. The nervous system was severely damaged and the lesions could not be repaired because of the nature of the tissue, leading to a permanent paralysis.

Polio, as a social disease, was first detected in Italy after World War I (1914-18), with a consistent upward trend in the number of reported cases. Between 1910 and 1920 in the Paediatric Clinic of the Rome University Hospital, there were 214 cases of «Heine-Medin disease», as polio was called at the time $\mathrm{e}^{4}$. The attention paid to this emerging disease increased due to the dissemination in the Italian medical press of the information pertaining to the epidemics that were occurring in many developed countries, especially after the 10th International Medical Congress in Berlin, where the Swedish paediatrician Karl Oskar Medin (1847-1927) reported a large number of clinical cases and carefully described the clinical aspect of the disease. This report had a strong impact and the medical community acknowledged the existence of a new epidemic of an old disease, which was acquiring new clinical and geographical dimensions. New epidemics in Sweden of the so-called «Heine-Medin disease», in 1899 (Stockholm), 1903 (Göteborg) and especially the devastating epidemic which took place in Stockholm in 1905, with more than 1000 cases, were described by Ivar Wickman ${ }^{5}$.

In the United States, after the 1907 epidemic in New York City (reported in 1910), the north-eastern part of the country was struck by a devastating epidemic, which was much more important than any previous one, with a rate of 28.5 cases per 100.000 inhabitants. As in cholera epidemics of the nineteenth century, this event engendered a strict quarantine, city-wide disinfection, denunciation and isolation of the cases, and forced treatment. However, the medical community immediately realized that the recognized cases might represent only $10 \%$ of the total of infected persons. As a consequence, while notification of cases could be useful, quarantine and isolation were impossible to apply. As for previous plagues and pandemics, health officers lost faith in the value of general public health measures (such as quarantine, disinfection, fumigations, isolation of the patients, etc.) for

4. Cannarsa, F. Contributo statistico sulla malattia di Heine-Medin in Roma dal 1901 al 1920. La Pediatria. 1924; 32: 215-221.

5. Wickman, Ivar. Acute poliomyelitis (Heine-Medin's disease). Journal of Nervous and Mental Disease. 1907; 16: 113. 
polio control. The measures were applied almost exclusively for psychological reasons, with the aim of calming public anxiety ${ }^{6}$.

The news aroused great interest in the medical press in Italy, especially in journals devoted to the whole medical community, such as Il Policlinico, Gazzetta Medica Italiana and Minerva Medica, and in paediatric journals such as the Rivista di Clinica Pediatrica, La Clinica Pediatrica and La Pediatria $^{7}$. In the first two decades of the twentieth century, however, the average number of cases in the whole country remained relatively low, with an absolute annual average number of cases of 581, and an annual mean incidence of 1.5 cases per 100.000 inhabitants. The incidence rose however to 4.5 in 1931-1940. During the same period, also in Italy, it became evident that there was a general increase in the age of patients, and as a consequence, in the severity of the disease and its permanent aftermaths.

In relation to other countries of southern Europe, polio was particularly common in Italy. In 1935 and after, a period of low frequency, more than 5 cases per 100,000 inhabitants were reported in the years 1936-1941, with a peak of 13.7 in $1939(6,000 \text { cases })^{8}$.

In 1936 a specific event made the polio epidemics particularly visible in Italy, creating vast alarm among the general population. Anna Maria, the youngest daughter of Benito Mussolini, the head of the Fascist government, contracted a severe form of polio. At the beginning the disease was misdiagnosed and confused with a non-specific form of whooping cough.

6. This point is openly recognized by Payne, Alfred M. Poliomyelits as a world problem. In: poliomyelitis. Papers and discussions presented at the third international poliomyelitis conference. Philadelphia: J. B. Lippincott Company; 1955, p. 391-400.

7. This interest was also reflected in the amount of scientific research devoted to this particular disease. For example, the physiologist Carlo Francioni, a pupil of Filippo Bottazzi, designed a special manometer to measure the pressure within the cerebrospinal liquid, as a diagnostic tool for the early stages of polio: Francioni, Carlo. Sulla pressione endorachidea in varie malattie dei bambini. Rivista di Clinica Pediatrica. 1911; 9: 161-210. On Francioni see Maggioni, Giorgio. Francioni, Carlo. In: Dizionario Biografico degli Italiani. Roma: Istituto dell'Enciclopedia Italiana; 1998, p. 50. Important contributions to the knowledge of the etiology of polio were made in the early 1930 by the pediatrician Guido Guassardo, who also tried to reproduce polio experimentally: Guassardo, Guido. Studi sulla riproduzione sperimentale della poliomielite anteriore acuta. Pathologica. 1930; 22: 525-534; Guassardo, Guido. Considerazioni sull'etiopatogenesi della malattia di Heine-Medin. Pathologica. 1931; 23: 743-750. On Guassardo see: Burgio, Roberto G. Guassardo, Guido, In: Dizionario biografico degli italiani. Roma: Istituto dell'Enciclopedia Italiana; 2003, p. 60.

8. Lamma, V. Considerazioni sulla distribuzione per sesso ed età dei casi di poliomieliti denunciati in Italia, Annali della Sanità Pubblica. 1958; 19: 131-140. 
The family decided to take the child to a villa in Tivoli, with the aim of exposing her to «better air», but she suffered a violent fever, vomiting, neck stiffness and pain in her limbs. Polio was finally declared; the child recovered but was left with a severe paralytic scoliosis.

The direct involvement of the Duce's family produced a series of relevant initiatives in the field of prevention of the disease and treatment of its consequences. A vast social campaign was launched. From 1936 the declaration of cases to public health officers was made mandatory and health authorities began to collect accurate statistical data, even though, as in other contexts, the abortive or non-apparent cases could not be isolated, because of the lack of serological tests of the vast majority of the population.

The government also created special institutes for the treatment of polio, a very innovative measure at the time, the most important being the Istituto Principe di Napoli in Ariccia, a small town near Rome. This Institute played a major role in the treatment and rehabilitation of polio patients in the following decades ${ }^{9}$. A special law for «the assistance and the care of poor patients affected with the sequelae of acute anterior poliomyelitis» was issued by the Fascist government on June 10, 1940, in the same session that declared war on Great Britain and France.

In the following years the notification-rate decreased (not only because of the war), and stabilized at between 5 and 6 cases from 1945 onwards, in spite of the severe outbreak in 1953. Indeed mortality due to polio decreased in Italy after 1921, notwithstanding the increase in the number of cases notified. The lethality passed from 18.6 in 1936 to 8.5 in 1953. This might have been due simply to the improvement in notification and data collection. After the 1953 epidemics the incidence remained almost stable until the end of the decade when it peaked, in 1958 at 8,377 cases and 1,173 deaths (16 cases per 100,000 inhabitants) ${ }^{10}$.

During this new phase the Italian medical and public health community were finally convinced that the disease spread through the medium of mild cases (polio minor), also called «abortive polio». Polio was then considered as a highly contagious disease, with a limited number of acute clinical cases, characterized by paralysis, and a much higher number of infections with mild

9. Spina, Nunzio L'Istituto ortopedico di Ariccia per l'assistenza ai poliomielitici: Opera di carità e progresso. Giornale Italiano di Ortopedia e Traumatologia. 2011; 37: 215-224.

10. Crovari Pietro. History of polio vaccination in Italy. Italian Journal of Public Health. 2010; 7 : 322-324. 
or absent clinical manifestations. This finally produced a new framework for the understanding of the clinical and epidemiological features of the disease and demonstrated the need for the classification of the different forms.

In this period, the distribution within the country closely correlated with the quality of sanitary conditions and health education. Children from the lower socioeconomic segment of the population acquired infection and consequent immunity at an earlier age than did those in the higher social classes which produced an inverse correlation between health condition, as measured by Infant Mortality Rate (IMR), and polio cases per million of the population. Italy in the 1930s and 1940s had an IMR similar to poor countries like Portugal and Greece (75 infant deaths per thousand) which in the literature of the time was considered to be the critical level for the shift from a low to high rate of severe polio epidemics. Italy at the time had 5.5 cases of severe polio per 100,000 inhabitants. By comparison, in the same period, Switzerland had an IMR of about 38 and a severe polio rate of about 14 per 100,000 inhabitants.

The analyses of the epidemiological data, available from 1925 to 1949, showed the shift in the incidence of the disease in different age groups; a significant decrease in the number of deaths among younger children (0-4 years), and an increase in people over the age of 20, while the other age groups remained relatively stable. This change was attributed, as in other countries a few decades before, to the enhancement of hygiene conditions and the increased urbanization of the population ${ }^{11}$.

With many decades of delay in relation to the other industrialized countries, in Italy after World War II, the disease became common among adolescents and when the level increased it also reached a significant number of young adults. This corresponds to the changing distribution of the populations, internal migration from the South to the North and intensive urbanization around the industrial cities (Turin, Milan, the Venetian region, the Liguria and the Emilia-Romagna Regions).

The epidemiological data showed that the disease was specific to the population itself and not to the conditions under which the people lived.

11. Russo, Giuseppe. Variazioni nell'incidenza per età della mortalità per poliomielite anteriore acuta in Italia. Rendiconti dell'Istituto Superiore di Sanità. 1951; 14: 824-838; Russo, Giuseppe. Contributo allo studio delle variazioni nell'incidenza per età della poliomielite anteriore acuta in Italia. Rendiconti dell'Istituto Superiore di Sanità. 1955; 18: 430-445. 
The environmental factors were much more important than the geographical features.

Giulio A. Maccacaro published in 1952 an accurate analysis of the incidence of polio in different age groups, noting clearly the increase of virulence in young adults ${ }^{12}$. In this paper he quotes an important passage from a paper by Ames:

«shifts in age with the passage of time are subject to various interpretations, many of them not considering adequately the influence of changes in environmental conditions which in turn influence intensity of exposure. If, in poliomyelitis, we are dealing with decreasing exposure, we have as a result the gradual accumulation of susceptible persons in the population, and thus a satisfactory explanation of the present-day recurrent pattern of poliomyelitis» ${ }^{13}$.

In the 1950s, fast moving socioeconomic factors, with rapid migration from rural to urban industrial areas, created a complex situation, producing an unequal impact of the disease among the different areas of the country, as northern and southern parts were, and still are, widely different in their socioeconomic status.

Through the first half of the twentieth century a large part of the Italian population lived in large, complex and relatively isolated family settings. In popular culture the situation was defined as la miseria, misery, as in the very famous movie with the two most well-known Italian comic actors of the 1950s, Totò and Peppino De Filippo (1954), illustrating two different worlds: on the one hand, the rich nobility and, on the other, people living in conditions of extreme poverty and overcrowding, hungry and exposed to every kind of infection and nutritional deficiency diseases.

Until the 1950s, Italy was an agricultural and rural country, although industrialization was very developed in some regions of the north, including in agriculture (rice cultivation in the provinces of Vercelli and Novara). After World War II there was a very rapid process of urbanization and industrial development, especially with small and medium industries, distributed

12. Maccacaro, Giulio. Interpretation of the aging of acute anterior poliomyelitis. Annali Sanità Pubblica. 1952; 13 (5): 1373-1387.

13. Ames, Wendell R. Variations in the age selection of poliomyelitis associated with differences in economic status in Buffalo, N.Y., 1929, 1944, and 1949. American Journal of Public Health. 1951; 41: 388-395. 
largely in the North, with a spectacular increase in the economic well-being of a large part of the population (the miracolo italiano) ${ }^{14}$.

Until the end of the Fascist period in 1945, Italian governments did very little to improve the quality of life in rural areas, notwithstanding strict public health legislation, which was only rarely put into practice, because of the scarcity of funds and the poor quality of the public administration and political power.

The Fascist government, however, made an important effort to develop a national health care system and improve the national infrastructure by creating specialized institutions (such as the Opera Nazionale per la Maternità e l'Infanzia, ONMI) and an Institute for the Collection of Demographic and Epidemiological Data, the ISTAT, set up in $1926^{15}$. The public initiatives, however, concentrated on the «big diseases», in particular malaria and tuberculosis, with an important effort made in urban sanitation, land reclamation, and propaganda.

Compared to the other European countries, Italy went through its demographic, economic, and epidemiological transitions very recently, and the transition was compressed into a short period. At the beginning of the twentieth century Italy's birth and death rates were among the highest in Europe, with figures typical of the «first phase» (the age of pestilence and famine) and partly of the second (the age of receding pandemics), according to the classification proposed by the theory of epidemiological transition ${ }^{16}$. However, only a few decades were needed to reach the third phase (the Age of Degenerative and Man-Made Diseases), with a very low fertility rate and a death rate almost identical to that of other European countries.

\section{The social and scientific reactions to the polio epidemics}

After World War II, the birth of the new and democratic Italian Republic and the developments that were taking place in the international community,

14. Cederna, Camilla. Nostra Italia del miracolo. Milano: Longanesi; 1980; Crainz, Guido. Storia del miracolo italiano. Culture, identità, transformazioni fra anni cinquanta e sessanta. Roma: Donzelli Editore; 2005; Ginsborg, Paul. Storia d'Italia dal dopoguerra a oggi. Torino: Einaudi; 2006.

15. Cassata, Francesco. Il fascismo razionale: Corrado Gini fra scienza e politica. Roma: Carocci; 2006.

16. Omran, Abdel R. The epidemiological transition: a theory of the epidemiology of population change. Milbank Memorial Fund Quarterly. 1971; 49: 509-538. 
in particular with the origins in 1948 of the World Health Organization, a new sensibility arose as to the rights of ill people and the need to improve the health of the whole population.

The Constitution of the Italian Republic, approved in 1948, precisely the same year as the World Health Organization Constitution, states in its article 32: «The Republic safeguards health as a fundamental right of the individual and as a collective interest, and guarantees free medical care to the indigent».

This created a new cultural context, which favoured enormously the initiatives to counteract the sanitary problems of the country, including the increasingly acute problem of polio, and in favour of the care of ill and disabled people. In 1952, Luigi Spolverini, director of the Ariccia specialized clinics for the treatment and rehabilitation of polio patients ${ }^{17}$, defined polio as a nation-wide problem and a «social scourge»:

«[Polio is] a tragic reality perhaps worse than that offered by the three other social scourges - tuberculosis, rheumatism with cardiopathic consequences, and cancer. To the last ones, notwithstanding their importance from the point of view of the number of people affected, one cannot apply such a dramatic picture as that described for poliomyelitis» ${ }^{18}$.

In the late 1940s and 1950s, the Italian medical and scientific community, which had remained largely isolated under the Fascist dictatorship, developed an intense activity, favoured by the new financial resources made available first by international aid (the Marshall plan) and then by the socio-economic «miracle». A scientific community was created and fully integrated at a very high level in the international scientific and medical world. Italian paediatricians, hygienists, virologists and physiotherapists played an important role in the international efforts to cope with the polio epidemics, as the disease had become a «world problem» ${ }^{19}$, which could not be solved at a purely local level.

17. Spolverini, Luigi. Organizzazione e funzionamento di un Istituto per la cura dei poliomielitici. Annali della Sanità Pubblica. 1950; 11: 3-82.

18. Spolverini, Luigi. II problema della poliomielite. Rassegna Clinico-Scientifica. 1948; 24: 137-143; Spolverini, Luigi. Il problema della poliomielite «Flagello sociale» Annali della Sanità Pubblica. 1952; 13: 387. Unless stated otherwise, all translations are mine.

19. Payne, n. 6. 
«The transformation of the relatively uncommon "infantile paralyses" of the 19th century into "epidemic poliomyelitis" of almost worldwide distribution presents today one of the most formidable public-health problems» ${ }^{20}$.

Immediately after its creation, the World Health Organization established a commission of experts on polio, which played a fundamental role in coordinating the activities at national and international levels, spreading the new discoveries and techniques, and increasing knowledge of the disease, its epidemiology, the therapeutic and the post-disease treatments.

The Interim Commission of WHO, during its 5th session, approved the proposal of the Irish delegation to include poliomyelitis in the agenda of the First Health Assembly. At the Eleventh session of the First World Assembly on July 8, 1948, attention was drawn to the worrying increase in the number of cases of polio. The French delegate René Dujarric de la Rivière, a Pasteurian physician, underlined that «the spread of poliomyelitis had reached disquieting proportions» ${ }^{21}$. In the same session, the Swedish delegate, Dr Rolf Bergman, a paediatrician who had carried out an extensive epidemiological survey on polio in Sweden ${ }^{22}$, suggested that the studies should cover all the aspects of the disease, «epidemiological, clinical and social». The Italian delegate, Vittorio Puntoni, professor of microbiology (1926-43) and then of hygiene (1943-57) at the University of Rome, and a specialist in the prophylaxis against infectious diseases ${ }^{23}$, supported this attitude, which corresponded perfectly to what the Italian medical community was creating in Italy.

Acknowledging the rise in increasingly severe forms of poliomyelitis in numerous countries, and supporting the organization of international conferences, already planned in Brussels and New York, the First World Assembly requested a report, which was submitted to the Second World Health Assembly, which met in Rome from June 13 to July 2, 1949. The series of World Polio Congresses which started in 1948 played a fundamental role in fostering international cooperation against polio. The following Congresses were held in Copenhagen 1951, Rome 1954, Geneva 1957, and

20. WHO expert committee on poliomyelitis (1952), WHO technical Report, Series 81.

21. WHO. First world health assembly, eleventh meeting, 1948, p. 143.

22. Bergman, Rolf. Poliomyelitis and its prognosis in Sweden. Condition and capacity for work after nine years' observation. Acta Paediatrica. 1945; 32: 298-304.

23. Puntoni, Vittorio. Trattato di igiene. Roma: Tuminelli; 1948; Puntoni, Vittorio. Epidemiologia e profilassi. Roma: Tuminelli; 1951. 
again Copenhagen 1960. The congresses were funded by the American National Foundation for Infantile Paralysis and the proceedings were regularly published by the J.B. Lippincot Company.

The Rome conference, arriving after the 1953 epidemics, which touched practically every industrialized country, was particularly important as it clearly defined the agenda, proposing a global view on the different aspects: clinical observations of the acute cases, orthopaedic treatment, rehabilitation, physical medicine, and social aspects of the epidemics. The last points were particularly emphasised by the Italian delegates, who insisted on the development of new methods for the rehabilitation of polio victims and their insertion in the work place, an objective that could be realized only by public assistance and in the context of accurately designed legislative measures. This attitude was clearly expressed in a paper published by Saladino Cramarossa, General Director of the Public Health and Hygiene Department of the Ministry of Internal Affairs ${ }^{24}$.

\section{The 1958 epidemics}

In the 1950s the incidence of polio in Italy was continuously increasing, particularly in the Central and Southern Regions. After the epidemic peak in 1953, there was a decrease in the number of cases in the years 195455, but from 1956 on this number started to increase again and the 1958 epidemics appeared to be the most serious experienced in Italy. A total of 8,394 cases were reported, with an incidence rate of 16.7 per 100,000 inhabitants, whilst death cases were 1,173 , with a lethality of $14 \%$ and an overall mortality of 2.34 per 100,000 inhabitants. Such figures were the highest since the beginning of the registration of polio cases in $1924^{25}$.

The origins of the new epidemics in the early 1950s were correctly connected to the evolution of hygiene and the changing way of life of the population, but in some circles it was suggested that responsibility for the polio epidemics could be attributed to the vaccination campaigns, notably against diphtheria, with a vaccine made available in Italy since the late 1920s. The vaccination against diphtheria was made mandatory in Italy in 1939

\footnotetext{
24. Cramarossa, Saladino. Aspetti sociali della poliomielite. Minerva Medica. 1954; 45: 1496-1497.

25. Realmuto, A.; Scozzarella, E. La poliomielite in Italia e le manifestazioni epidemiche nel 1958. Annali della Sanità Pubblica. 1959; 20: 879-936.
} 
but in fact it was implemented at a national level only in the early 1950 s. Hence the suspicion of a possible causal link with the polio epidemics. On October 22nd, 1952 a special meeting was organized by the National Health Council, chaired by the well-known clinician Cesare Frugoni, with a report by the General Director of Public Health, Saladino Cramarossa. Practically all the experts on polio were present and the result was the complete exclusion of any causal link between vaccinations and polio ${ }^{26}$.

The epidemic peaks and the consequent high cost of long term care needed for children and young adults disabled by the disease finally made the problem of infantile paralysis a central aspect of health policy. The 1953 and 1958 epidemics had left a backlog of patients with the paralytic and disabling consequences of the devastating disease. A national public effort was needed not only from the State but also from many philanthropic

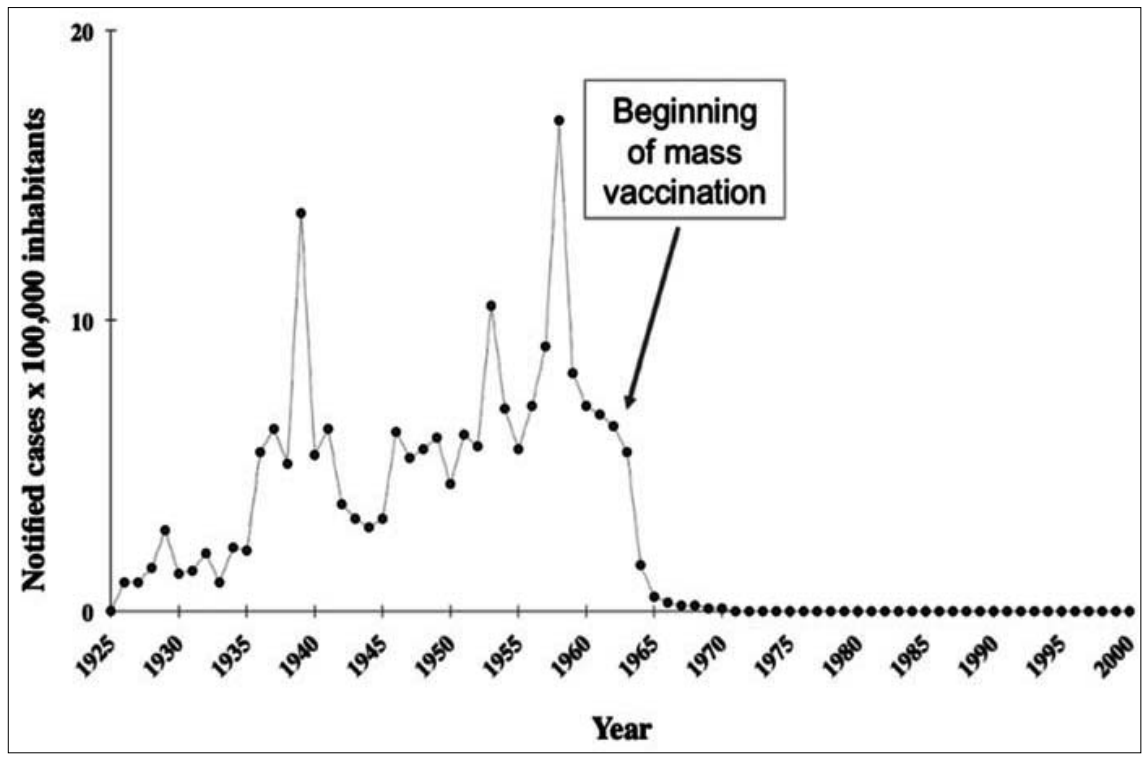

Figure 1. Notified cases of poliomyelitis in Italy. Source: Cravari, Pietro. History of Polio Vaccination in Italy, Italian Journal of Public Health. 2010; 7 (3): 322-324 (323).

26. Rosa, Alberto; Olivo, Romano. Vaccinazione antidifterica e poliomielite, Athena. Rassegna mensile di biologia, clinica e terapia. 1954; 20: 55-59. 
organizations, foundations and associations that were created in this period to fight against the disease and its consequences.

\section{The different actors}

As long as the number of cases of infantile paralysis had remained isolated, no special institutions were needed and the ill children were treated in the paediatric and orthopaedic divisions of the main hospitals. Within the national system of public health, first introduced in Italy by the law of December 22, 1888 (Crispi's Law), at the end of the nineteenth-century a few orthopaedic institutions reserved for children were opened, mainly devoted to the treatment of rickets, a disease widely spread among the poorest part of the Italian population. Most institutions, however, were of a private nature and were created by religious and humanitarian associations.

In 1881 the Orthopaedic Institute for Rachitic Children opened in Milan as a component of the School-Asylum for Rachitic Children, which had been founded by the philanthropist Gaetano Pini in 1875. Similar institutions were created in Genoa (the orthopaedic institute created by the Cristoforo Colombo Association), Cremona, Bergamo, Verona, Turin and other Italian cities. In Turin there was also a department of infantile surgery and orthopaedics within the Childrens Hospital Regina Margherita.

The isolated cases of infantile paralysis were treated in these institutions, but in 1900 the Institute Lina Raschieri was created in Naples which associated the treatment of deformities produced by polio with those caused by rickets. In this institutional context, care was given not only to children but also to adults struck by polio which at the beginning of the twentieth-century was becoming a more common situation. The same policy was followed by another leading actor of polio history, the Orthopaedic Institute Rizzoli in Bologna.

The surgical treatment of the deformities in the inferior limbs caused by polio included the transplanting of tendons, suggested and practiced by Alessandro Codivilla from $1899^{27}$ and arthrodesis (a technique also known

27. Codivilla, Alessandro. On the means of lengthening in the lower limbs, the muscles, and tissues which are shortened through deformity. American Journal of Orthophedic Surgery. 1905; 2: 353; Peltier, Leonard F. The role of Alessandro Codivilla in the development of skeletal traction. The Journal of Bone \& Joint Surgery. 1969; 51: 1433. 
as syndesis, based on the artificial induction of joining between two via surgery) was developed in the 1930s mainly by Carlo Marino- Zuco in the Orthopaedic Clinic or Rome university hospital ${ }^{28}$.

In the late 1930s, after an epidemic peak, the number of the specialized polio institutions increased in the whole country. In Ancona an autonomous division of infantile orthopaedics was created within the department of paediatric surgery. In 1939 Gaetano Salvioli organized a special centre for the treatment of poliomyelitis in Bologna, within the paediatric clinics. In 1936 the municipality of Rome had built the new hospital for infectious diseases Lazzaro Spallanzani with about 300 beds distributed in 15 buildings. In this complex a new pavilion for the treatment and rehabilitation of polio patients was activated in 1939.

The outbreak of World War II obviously blocked any further institutional development, and at the end of the war the economic and social conditions of the country were extremely difficult. However, a series of incisive measures improved the situation quite rapidly and in the early 1950s, in parallel with the beginning of new polio epidemics, a national effort was made to cope with the disease and its consequences.

In 1945 the High Commissariat for Hygiene and Public health (ACIS) was established, headed by a Commissioner appointed by the Prime Minister. The Commissariat had two departments (medical services, veterinary services) and an office for the control of pharmaceutical production ${ }^{29}$. The Commissariat also controlled the Central Institute of Health (Istituto Superiore di Sanità), devoted to teaching and research, both epidemiological and fundamental. At the local level the Prefect was the local health authority, with a Provincial Health Office and a Provincial Public Health Laboratory. Each municipality appointed a «sanitary officer», who in general was a medico condotto, a public or family physician, a figure which existed in Italy in the Middle Ages, when each «Comune» usually had a physician under contract for the cure and the care of the poor.

28. Bonadies, Antonio; Marino-Zuco, Carlo, eds. La poliomielite. Atti del Convegno sulla poliomielite, Roma 18 maggio 1959. Città di Castello: Società Poligrafica Editoriale; 1959.

29. The Alto commissariato per l'igiene e la sanità pubblica, published also a new journal Scientia Medica Italica: a review of the Italian contribution to the development of medicine and biology. From 1950, it was published in English, German, and French: Canaperia, Giovanni A. Organisation of Public Health Service in Italy. Scientia Medica Italica. 1950; 1: 180-188. 
Health and welfare for mothers and children was directed by the Opera Nationale per la Protezione della Maternità e dell'Infanzia (ONMI), which directly managed obstetrical and paediatric clinics. In the 1950s the ONMI had about 4,000 paediatricians and 2,500 obstetricians.

This public health structure made an effective fight against infectious diseases possible, especially tuberculosis, intestinal infections, malaria, diphtheria and brucellosis, at that time a real scourge in Italy. A national network of pharmacies made available at a price controlled by the State all the new drugs, such as antibiotics.

In the early 1950s, however, scarce attention was given to poliomyelitis, perhaps because the epidemiological data seemed to show a decrease in its frequency. For example, from March 1950, the High Commissariat developed a program of health education by means of scientific movies, projected in schools, barracks, hospitals, and public offices. The first films were devoted to tuberculosis, malaria, and brucellosis and there was no mention in the project of polio ${ }^{30}$.

In the immediate post-war period, injured and crippled children constituted a significant social problem. At that time it was estimated that there were in the whole country more than 15.000 severely disabled children, most of whom had been injured to a greater or lesser degree during military actions, and the vast majority of whom were civilian airraid casualties. Others had been injured during the actual street fighting, especially in Naples, Rome, and the Northern part of Italy. Furthermore, in the late 1940s many casualties had been caused only indirectly by the war; for instance, children who had received their injuries by finding and playing with unexploded bombs, or stepping on undiscovered land mines. In the early 1950s to this great number of war casualties were added children injured by street accidents, poliomyelitis and other disabling diseases.

A very active aid program was organized for the Don Gnocchi Foundation at Rome by the World Health Organization and the United Nations Invalid Children's Emergency Fund, which provided a full range of physiotherapy and gymnasium equipment and trained a number of the Italian Red Cross nurses in basic physiotherapeutic techniques.

30. L'educazione igienico-sanitaria mediante il cinematografo, nuova attivita dell'A.C.I.S. Notiziario dell'Amministrazione Sanitaria. 1950; 3: 81-84. 
The attention to the plight of these children was increased by the action of a priest named Don Carlo Gnocchi ${ }^{31}$, a military chaplain of the Alpine regiment fighting in Albania and on the Russian front during the war. At the end of the war, he travelled throughout Italy to personally assist the families of his fallen soldiers and give them any letters or belongings that he had had the opportunity to collect. During this experience, he realized that the problem then was assistance to the family who had lost their men and often their house, and especially the large number of children who had lost limbs because of the bombing or the land mines still remaining in the Italian countryside. He realized that they needed both medical treatment for their disabilities and also good cultural and technical training to be able to find a job and a place in social activities. These objectives were beyond the means of families and Don Gnocchi therefore created the «Pro Juventute Foundation» which with the support of many private sponsors and powerful Church leaders undertook a national campaign. Through radio appeals, interviews in the press, street collections and other means, he managed to raise the money necessary to create specific institutions for the disabled children in order to provide them with housing, food, medical care and education. In a few years seven centres were created at Rome, Turin, Florence, Salerno, Parma, Pessano, and Inverigo. Four of the Centres were for boys, two for girls, while the centre at Parma admitted both boys and girls.

The Centres were at first intended purely as schools and clinics but at a later date Don Gnocchi realized that the children needed a job in order to live an ordinary life and therefore set up workshops in some of the Centres where crafts such as tailoring, carpentry, leather work, and pottery could be taught. At the same time, the Centres provided training for nurses and doctors specializing in the treatment of disabled children and Don Gnocchi's centre in Rome became a permanent training school for physiotherapists ${ }^{32}$.

31. Agnini, Gaetano. Don Carlo Gnocchi, alpino cappellano. Prefazione di Tettamanzi Dionigi. Milano: Mursia; 2011; Belski, Lagazzi Ines. Don Carlo Gnocchi. L'apostolo dei mutilatini. Modena: Edizioni Paoline; 1968; Cosmacini, Giorgio. La mia baracca. Storia della fondazione Don Gnocchi. Bari: Laterza; 2004; Rumi, Giorgio; Bressan, Edoardo. Don Carlo Gnocchi. Vita e opere di un grande imprenditore della carità. Milano: Mondadori; 2002.

32. Boyle, A. C. Discussion on the present status of physical medicine in the countries of Europe. Proceedings of the Royal Society of Medicine. 1953; 46 (11): 982-985. 
At a later date, the Italian Government directly financed the activities of the foundation, which had become the Don Gnocchi Foundation. The number of centres reached 28 , distributed over ten Italian regions, with more than 3,500 beds and about 5,000 operators. In the biggest centres the Foundation performed scientific research and two of them were recognized by the Ministry of Health as research hospitals of national interest in the field of rehabilitation and in the application of advanced biotechnology for orthopaedic, neurological, cardiology and pulmonary rehabilitation.

In the early 1950 s and especially after the 1953 epidemic peak the centres of care and rehabilitation had to treat the increasing number of children affected by polio. The situation was very difficult because of the lack of a sufficient number of specialized structures and especially adequate equipment. The very expensive technology remained for many years in scarce supply and many children died because of the lack of iron lungs, and the treatment of the survivors was often limited to surgery and the provision of mechanical aids ${ }^{33}$. Because of the high cost of permanent care, an ethical debate developed as to the quality of life of the patients whose life was saved by the machine. The doubts about the decision to put a severely sick child in the machine were frequent among doctors as well as the patients or their family.

Different institutions were in charge of care for the different stages of the disease: acute phase, convalescent phases, rehabilitation, chronic phase and coping with permanent disablement. The immediate treatments of the new cases were carried out in the paediatric clinics of the main hospitals and especially by specialized centres that had been created by the High Commissariat for Public Health, which treated an average of 4,000 annual cases in the years preceding the large 1958 epidemic.

The acute problem was the scarcity of trained physiotherapists for the treatment of the convalescent children. Specialists attended courses in Great Britain, thanks to fellowships granted by World Health Organization but it was difficult to apply the new techniques in the Italian institutions, because of the lack of specialists and adequate structures. After the war the only specialized Institutes for the treatment of infantile paralysis was the

33. Battini, Danilo; Tomaselli, Salvatore. Contributo allo studio del problema assistenziale dei poliomielitici in Italia con particolare riguardo alle speciali istituzioni di cura. Annali della Sanità Pubblica. 1951; 12: 1969-1998. 
Istituto Principe di Napoli in Ariccia, the Rizzoli Institute in Bologna and in 1950 a large hospital was set up at Malcesine, in the region of Lake Garda.

The Pontificia Opera di Assistenza (Pontifical Council of Assistance) created a sanitary service specialized in the care of children affected by infantile paralysis in the Clinics of Occupational Diseases in Rome and in a summer camp at Lido di Ostia where 250 children per day could be treated in two turns, for 90 days.

The Ariccia Institute had 170 beds, divided into three departments: physical therapy, orthopaedics, and kinesitherapy. The last was considered the most important, based on a series of passive and active movements, such as massages and exercises. The aim of the treatments was a rapid functional recovery; to prevent contracture and the abnormal and permanent shortening of muscles resulting in deformity, to maintain a normal circulation in the affected limbs, to limit surgical intervention to the correction of deformity and the fitting of orthopaedic appliances when necessary.

Particular attention was given to exercise and gymnastics in the swimming pool, as the movements resulted easier, because of the support of the water. A tabernacle placed at the edge of the swimming pool contained the motto Vitam aquae natura donat. Infaustae Naturae reddit aqua vitam (Nature gives life in water. Water gives back life to inauspicious nature).

The average length of hospitalization was 180 days for the less severe cases and more than 500 days for the cases with severe consequences. The patients ranged in age from 14 months to 14 years, and provision was made for the suitable education and professional training of the older children $^{34}$. The Centre rapidly became a national training institution for the «orthopaedic technicians» and «rehabilitation therapists».

In the 1950s new centres specialized in the rehabilitation of polio patients were created, especially in the Southern Regions, those most affected by the new epidemics (Reggio Calabria, Bari, Napoli).

\section{The vaccination campaign and the elimination of the disease}

In parallel with the experiences in many different countries, experimentation with vaccines started quite rapidly also in Italy. Debates took place over

34. Spolverini, n. 17. 
many years on the respective advantages and especially liability and ease of use of the two main types of anti-polio vaccines: Salk's inactivated vaccine (IPV) and Sabin's oral live attenuated vaccine (OPV). The Salk vaccine was approved in 1957 and the Ministry of Health made free vaccines available to preschool children and schoolchildren. The product was also sold in pharmacies ${ }^{35}$. A national meeting was organized in Rome at the Orthopaedic Institute and this was the occasion for a careful analysis of the scientific, medical, and social situation of the polio epidemics, the expression at the same time of the fear of new epidemics- peaks and the expressed hope for treatment originated by the preliminary results obtained through immunization ${ }^{36}$.

The research efforts conducted mainly in the U.S. for the preparation of a polio vaccine, were followed very closely by the Italian manufactures of vaccines, who rapidly became equipped for the preparation of both IPV (Istituto Sieroterapico Italiano in Naples) and OPV (Sclavo Institute at Siena and Istituto Sieroterapico Milanese in Milan).

The Istituto Sieroterapico e Vaccinogeno Toscano founded in 1904 by Achille Sclavo, professor of Hygiene at the University of Siena ${ }^{37}$ in his country house, had acquired solid experience in the production of sera and vaccines. Meanwhile the director of the Istituto Seroterapico in Naples, Professor Michele Pontecorvo had also developed special techniques for the production of the vaccine.

The extensive use of the Salk vaccine from 1958 to 1963 did not prevent the annual occurrence of thousands of paralytic cases of poliomyelitis in Italy. Studies showed that many batches of Salk vaccine used in Italy had low immunogenicity ${ }^{38}$, and these years were characterized by lively scientific debate. Following the U.S., some experts considered that they should still focus on the inactivated vaccine, improving its immunogenicity, while others supported the use of Sabin's live attenuated vaccines.

The study of the second type of vaccine had started in parallel to that of the inactivated vaccine, but the time needed for its preparation and

35. Santopadre, Gaetan. Primi risultati sulla vaccinazione antipoliomielitica in campo umano con vaccino allestito con virus inattivati tipo Salk. Annali della Sanità Pubblica. 1958; 19: 359.

36. Bonadies; Marino-Zuco, n. 28.

37. Sclavo, Achille. Autobiografia scientifica. L'Igiene Moderna. 1954; 1-2: 133-134.

38. Crovari, Pietro. History of polio vaccination in Italy. Italian Journal of Public Health. 2010; 7: 322-324. 
testing was longer because of the delicate issue of security connected with the use of a live virus vaccine, even though attenuated. Strains attenuated by selection in the laboratory of viral clones with reduced virulence had been produced by different research groups (Sabin, Kroprowski, Cox) and numerous controlled clinical trials had been conducted or were in the pipeline, especially in Eastern European countries (Poland, Czechoslovakia, East Germany, etc.).

In November 1955, a meeting on polio vaccination took place in Stockholm and Albert B. Sabin reported progress with live virus immunization. In 1956 the WHO announced the results obtained by Koprowski, who had immunized 150 children using strains different from Sabin's, with positive results: «antibodies have persisted for five years after a single oral administration of this particular virus» (OMS, 1956). In the same year, a medical team from the Soviet Union visited the United States to study poliomyelitis and finally the Soviet medical establishment decided to use Sabin's vaccine in a mass immunization program later that year. The success of these studies and trials eventually persuaded the public health authorities in the US to switch from the inactivated vaccine to the live, attenuated one. Sabin's vaccine was chosen, licensed, and approved for use in the US in 1961.

In Italy, the Sabin and Cox strains were tested at the Institutes of Hygiene in Milan and Genoa respectively. In 1959 Augusto Giovanardi, director of the Institute of Hygiene in Milan, published the preliminary results of the experimentation in Italy of the Sabin attenuated vaccine ${ }^{39}$. The results seemed to be extremely positive and the medical community was convinced of the need to start a mass vaccination campaign using OPV. The Sabin-type vaccine seemed to produce a marked state of immunity, but also resistance against re-infection by wild polio viruses in the alimentary tract (intestinal immunity). That was considered a barrier to the spread of wild virus in the population, which could in such a way acquire a certain amount of protection.

The positive attitude of the medical community was amplified by the national press. On August 31st, 1962, an article in the newspaper La Stampa openly asked the public health authorities, «Why is the Sabin vaccine not

39. Giovanardi, Augusto et al. Vaccinazione di adulti e bambini con il virus poliomielitico, vivente ed attenuato secondo il metodo Sabin. Minerva Medica. 1959; 50: 3847-3851. 
used?». The article refers to the results obtained by the Italian laboratory research and trials and also noted the advantages of the OPV, which was easier to administer to children. In a country like Italy, where economic factors and the socioeconomic structure made it difficult to reach young children to give them many successive shots with inactivated vaccines, the use of OPV could limit to three or four the number of doses to be given orally. The shift from inactivated vaccine to live vaccine could make vaccination possible on a larger scale and therefore increase the coverage of the vaccination campaign.

The new technique rapidly gained the support of families, physicians, paediatricians and public health officers. Finally in 1964, noting the results obtained using available vaccines and the prospects afforded by live attenuated vaccine, the Italian Ministry of Health decided to launch a campaign of mass vaccination, using Sabin's Oral Poliovirus Vaccine (OPV).

After the careful training of healthcare workers and the dissemination of information to the public through the media, a well organized and highly participatory vaccination campaign was set up and put in motion. Monovalent vaccines were administered by the Hygiene and Public Health services and in preschool educational institutions and primary schools. The OPV was given to children by dropping two drops of vaccine on a sugar cube.

The vaccines were produced in Italy under license. Although numerous pharmaceutical companies produced the vaccine globally, Sabin closely monitored, approved, and often inspected its manufacture to ensure the maintenance of quality production standards. In Italy in 1963 Sabin selected the Sclavo Institute for the production of his polio vaccine. The Sclavo Institute supplied all the monovalent vaccines and the supply of trivalent vaccine was divided between the Sclavo Institute and the Istituto Sieroterapico Milanese. As the vaccine needed to be stored at $-20{ }^{\circ} \mathrm{C}$, particular attention was given by the Public Health Services to the preparation of the delicate cold chain required for the transportation of the vaccine from the producers to the vaccination centres in the different regions of the country.

The month of March in 1964 was dedicated to the administration of the vaccine against type 1 poliovirus, the month of April to that of type 3 and the month of May to that of type 2. After the reopening of schools, in October of the same year, children were given a dose of trivalent vaccine.

The immunization coverage vaccination was very good everywhere, with excellent results in the Central and Northern Regions, where it often exceeded 90\%. Subsequently, in 1965, capillary actions identified a large 
number of non-vaccinated children and finally in 1966, in order to maintain a high level of immunization, polio vaccination was made mandatory for newborns (Law n. 51 approved on February 4th, 1966). According to a ministerial decree of May 25th, 1967, the vaccination was carried out with three doses of monovalent vaccine, respectively at month 3 (type 1), month 4 (type 3), and month 5 (type 2). A trivalent dose was given at month 10 and a second one at age 3 years. The immunization of the population was regularly checked by serological analyses, conducted mainly by the research group of the San Martino Institute in Genoa, directed by Fernando Luigi Petrilli ${ }^{40}$.

With the mass use of OPV early in 1964, the number of reported cases quickly dropped from an average of more than 3,000 per year during the four years prior to the use of oral vaccine to 254 in 1965, 147 in 1966 , 106 in 1967, and 87 in 1968. In this period most of the reported cases of poliomyelitis occurred in the Southern and Island regions where the percentage of children vaccinated during the campaign was much lower than in the Northern and Central regions of the country ${ }^{41}$.

In 1972 the schedule was changed by another ministerial decree: monovalent vaccines were replaced by a more practical trivalent vaccine, with a first dose at month 3, a second dose after 6-8 weeks, a third dose at month 10 or 11, but not within 120 days of the second, a final fourth dose at age 3, at least one year after the third.

During the vaccination campaign, particular attention was given to the possible production of polio cases by the vaccine and tests were carried out in the 1960s by the Genoa research group ${ }^{42}$. Successive analyses showed that in the period 1964-2000, vaccination with OPV produced a small number of vaccine associated paralytic polio (VAPP) and in consideration of the ethical aspects and the very positive epidemiological situation, in 2000 a different vaccination schedule (IPV-IPV-OPV-OPV) was introduced, based on the use of inactivated strains in the first two vaccinations and OPV in

40. Petrilli, Fernando Luigi et al. Difese immunitarie nei confronti dei poliovirus di alcuni campioni di popolazione a diversi anni di distanza della vaccinazione di Sabin. Annali Sclavo. 1971; 13: 391-410.

41. Giovanardi, Augusto. Effect of Sabin poliovirus vaccine on incidence of poliomyelitis in Italy. Jama. 1969; 209.

42. Petrilli, Fernando Luigi; Crovari Pietro. On the possible consequences of the diffusion of the virus after poliomyelitis vaccination with attenuated poliovirus vaccine. Giornale di Igiene e Medicina Preventiva. 1967; 8: 313-323. 
the following two. Finally in 2003 the use of live attenuated vaccine was abandoned and exclusively IPV was used for polio vaccination during childhood.

A total of 3,431 cases were reported in the years 1959-1963 (an average of 686 cases per year), 841 in 1964, 145 in the years 1965-1968 (36 cases per year), 199 in the ten-year period 1969-1978 (19.9 cases per year) and the number reached zero at the beginning of the 1980s. Since 1983 no new cases of polio have been reported in Italy and the serologic and epidemiological evidence at the beginning of 1980s showed excellent vaccination coverage in the country, with the exception of the region of Naples ${ }^{43}$.

During the whole period the epidemiological distribution in Italy continued to show a striking peculiarity, as polio remained an infant and childhood disease. In the 1958 epidemics, 85\% of the cases were children under age 5 (about 25\% in the first year, $50 \%$ in children 1-2 years old, and $10 \%$ in 3-4 years old). By comparison, in the USA the great majority of the cases concerned children in the age group 4-15 and 25\% were older than 15 years old. In Italy only $5 \%$ of the cases were older than 15 years.

\section{Changing attitudes in patients and the public}

In the first half of the twentieth-century in Italy, as in other countries, being handicapped was a formidable burden for the individuals, but also for the families and society as a whole ${ }^{44}$. Especially during the Ventennio - the Fascist dictatorship - the families with a disabled child felt ashamed of his or her presence, and sought to hide them. Society and culture, based on the model of physical strength and military attitude, marginalized and stigmatized the «invalid», a person not valid for military service and work. Often the severely disabled children were permanently locked up in special institutions, such as the psychiatric hospital, in large part because their families were unable to take care of them.

However, the situation changed dramatically in the post-war period, after the creation of the Italian Republic, the Constitution of which in article 38 stated that

43. Santoro, Regina et al. Serum antibodies in Italy. Bull. WHO. 1984; 62: 591-595.

44. Shell, n. 1. 
«Every citizen unable to work and without the necessary means of subsistence is entitled to welfare support (...) Disabled and handicapped persons are entitled to receive education and vocational training. Responsibilities under this article are entrusted to entities and institutions established by or supported by the State. Private-sector assistance may be freely provided».

Care for the disabled was no longer an act of mercy, but the respect of a fundamental right of the person, and the obligation of the authorities and institutions, public and private.

In the late 1940s and 1950s social and cultural attitudes changed and a new sensibility appeared in the society. The images of young people suffering from a severe handicap which had changed permanently their lives, were diffused in the newspapers and magazines and had a strong impact on the public. The great increase in the number of polio cases made it commonplace to meet young people in a wheelchair or wearing heavy iron braces and crutches. Many articles were published in magazines and newspapers, and particularly shocking were the pictures of polio patients in an iron lung, which looked like a prison.

This increased the fear of living with the sequels of the disease, with movement limitation, dependence, incapacity to work and walk, and the consequent loss of autonomy which produce a different kind of human condition. These strong images greatly increased sensitivity to polio problems, and made the national vaccination policies against such a horrible evil widely acceptable.

Besides the public institutions, new associations were created in the 1950s, such as the Lega Italiana per la lotta contro la poliomielite (LILP), established in Rome in 1954 under the presidency of Mario Longhena, which became a member of the Association Européenne contre la poliomyélite. Its main aim was to provide disabled people affected by polio with an active life.

The League, strongly supported by the High Commissariat for Hygiene and Public Health, with circular n. 110 of 14 November 1955 signed by its director, Tiziano Tessitori, fostered collaboration with existing institutions in the field of care for sick people, with particular attention to their reintegration into the workplace and society at large. The League immediately set out to organize a «Polio Day» on a national scale, based on the model of the American «March of Dimes», in order to collect money and raise public awareness of the disease.

These efforts also produced tension within the community of disabled persons and within the public health and political circles. Reintegration into 
the workplace was not easy in the Italian socio-economic situation, because of the very high level of unemployment and the underdevelopment of many regions. Furthermore, many disabled people asked for an «invalidity pension» and refused the offer of a job. This demand for assistance from the state was defined however as a sort of «paid idleness» ${ }^{45}$ as working was considered to be necessary for complete social reintegration and participation in the collective effort for the improvement of the quality of life.

\section{The origin of patient's associations}

A change of attitudes took place also in the patients themselves, who switched from fatalism and resignation to awareness that the mechanical aids were not a prison, but a way to recuperate fundamental physiological functions, such as breathing, walking and working. The mechanical devices were no longer a source of intolerance and stigmas, but tools to restore forms of life, in the hospitals, at school, in public places and at work. Attitudes changed from apprehension to the hope of turning inability into ability, acquiring a new mobility, even if limited. New ways of practicing sports and cultural activities were possible. If football became impossible, swimming was an alternative, and playing a musical instrument could replace more physical activities.

This resulted in efforts to create associations of patients and people with disability. A first attempt was made in 1939 in Bologna by a group of 40 disabled people, headed by Giordano Bruno Guidi. The war stopped these initiatives, but at the end of the hostilities, Guidi met with a small group of disabled people in the Camera del lavoro, the headquarters of the trade unions, the first Italian Association of Civil Invalids.

The activity of the association was mainly devoted to providing each disabled person with job opportunities and to include them in civil society. Polio patients were included in the activity of the association. In the first years of activities they were a small minority, but their number increased rapidly in the $1950 \mathrm{~s}$.

On October 6th, 1957 the Associazione nazionale fra invalidi esiti da poliomielite (ANIEP- The National Association of Polio Invalids) was officially

45. Cramarossa, n. 24. 
founded at Bologna University. The following day the first Assembly was held, totally composed of people with polio. The first President of the ANIEP was Professor Casimiro Olszewski, an intellectual who was totally paralyzed but endowed with a strong personality and vision. His movements were difficult and even his voice was uncertain, but he was helped by Giancarlo Selleri, a young person who in the following year became the director of the journal of the association La voce dei Poliomielitici. In 1957 the League also published an accurate bibliography on polio ${ }^{46}$.

The debate within the Association was lively and in 1962 a series of contrasting views provoked a split. Many members joined another association, the Associazione Nazionale Mutilati Invalidi Civili (ANMIC), also created in 1956 and headed for the next 40 years by Alvido Lambrilli. The ANMIC organized several «marches of the suffering», which had a strong impact on public opinion, thanks also to the images of disabled people disseminated through the new tool of communication, television. This campaign was designed to incite a sentiment of pity in the public, and this was strongly criticized by the ANIEP, which insisted on the contrary on the dignity of the person and the fight for a complete integration of the disabled person in society and in the workplace.

The movement for the rights of disabled people expanded and became influential, especially in favour of integration in the workplace and the fight against architectural barriers. In early 1962 the Minister of Health of the Italian Government, Angelo Raffaele Jervolino, received a delegation of the ANIEP and in October of the same year Parliament approved a law for the mandatory engagement of civil disabled persons (L. 5 ottobre 1962, n. 1539, pubblicata nella Gazz. Uff 12 November 1962, n. 287). Enterprises with more than 50 employees were obliged to hire at least one disabled person per 50 employees.

In 1971 a new law approved on March 30th (n. 118) extended health care to disabled people and made provision for their rehabilitation in adequate institutions and their full integration into the workplace and society, eliminating any kinds of obstacles in the access to school, sport, and leisure. These processes could be considered completed when in 1977 a new law for the organization of the didactic activities in school explicitly

46. Siggìa, Salvatore. Bibliografia italiana sulla poliomielite. Bologna: Tip. Regionale; 1957. 
mentioned the need to take disability into account in the evaluation, in order to obtain full integration.

Finally the law of 1978, which created the National Sanitary System -a national, improved structure for public health and welfare (law 881/78) - in article 26 stated that «the health services aimed at the functional and social recovery of subjects affected by physical, psychical or sensorial impairments are provided by the Local Sanitary Unitis».

Some patients acquired a high visibility in Italian culture, such as Rosanna Benzi, who had polio in 1962 at age 14 and was obliged to spend the rest of her life in an iron lung at the San Martino Hospital in Genoa. She accepted the dramatic new condition with great resilience, becoming a symbol for her incessant «longing for life». Benzi became famous in Italy when she received a personal letter from Pope John XXIII, who thanked her for showing such moral strength. She published an autobiography under the title The vice of living ${ }^{47}$ which in 1988 was made into a movie directed by Dino Risi.

Another relevant figure in Italy was Benedetta Bianchi Porro, who was struck by polio in 1936 at the age of three months and was hospitalized at the Istituto Rizzoli in Bologna. Luckily the disease was relatively mild, but left her with a permanent weakness and a shorter leg, which obliged her to wear heavy orthopaedic shoes, affected her walk and procured her the nickname zoppona (big lame girl) ${ }^{48}$. Her youth was as a consequence very difficult, but she showed a strong moral strength, as revealed by her diary, kept over many years and published after her death at the beginning of her beatification ${ }^{49}$.

\section{The post-epidemic problems. The post-polio syndrome}

The history of polio would not be complete without mentioning the appearance of a new syndrome linked to the polio epidemics, which is receiving wide attention from the scientific community and patients'

47. Benzi, Rosanna. II vizio di vivere. Vent'anni nel polmone d'acciaio. A cura di Paffumi Saverio. Milano: Rusconi; 1984.

48. Da Fara, Lorenzo. Benedetta Bianchi Porro. Padova: Carroccio; 1986.

49. Bianchi, Porro Benedetta. Scritti completi. A cura di Vena Andrea. Cinisello Balsamo: Edizioni San Paolo; 2006. 
associations. Decades after the acute illness, polio patients in the $1980 \mathrm{~s}$ started reporting increased fatigue and muscle weakness, accompanied by pain, with a consequent incapacity to carry on working and leading a social life. Once more, patients needed mechanical assistance which of course leads to anxiety and frustration. Because there was little in modern medical literature about delayed neurological changes in polio survivors, the initial response by many physicians was that the problems were not real and the reports were disregarded.

A 1962 British paper by K.J. Zilkha was the first to follow the course of muscle weakness in polio survivors over many years. In 1970, three British lung specialists reported polio patients who were experiencing not only muscle weakness but also «excessive fatigue», «breathlessness», an inability to concentrate, drowsiness, and «severe attacks of sleepiness». These patients also reported «abnormal sensitivity to cold, especially of the extremities ${ }^{50}$. Of all these health problems, however, the critical symptom of post-polio syndrome is new progressive weakness ${ }^{51}$.

At this point the new development was accepted by the medical community, and the first known clinical description of the syndrome was traced back to 1875 , when Raymond and Charcot published a short note reporting the history of a 19-year old tanner with previous infantile paralysis who presented with new paresis and atrophy in his shoulder ${ }^{52}$. The authors suggested as an explanation either a new spinal infection or overwork, as the patient was employed in hard labour.

An accurate clinical description of the post-polio sequelae was proposed in Italy by Palmucci and co-workers. This group of Italian doctors concluded that even if in the past literature only a few cases could be reported, the problem in polio survivors was «far from rare» and suggested that late-

50. These quotations are taken from Bruno, Richard. The polio paradox. Understanding and treating post-polio syndrome and chronic fatigue. New York: Warner Books; 2002.

51. Halstead, Lauro S. Post-Polio syndrome. Scientific American. 1998; 278: 36-41.

52. Fulgence Raymond is often mentioned in literature as «M. Raymond», but this a mistake given to the fact that in the original paper the name of the author is designated as «M. Raymond», where M stands simply for Monsieur: Raymond, Fulgence; Charcot, Jean Martin. Notes sur deux cas de paralysie essentielle de l'enfance. Atrophie musculaire consécutive. Gazette Médicale de Paris. 1875; 4 (4): 225-226. 
onset symptoms represented a «new process distinguishable from the old disease ${ }^{53}$.

In 1981 the first post-polio conference was organized and an epidemiology survey showed that about a quarter of individuals who had survived paralytic polio in childhood had developed the symptoms decades after recovering from the acute infection. This condition was named post-polio syndrome (PPS) in $1986^{54}$. As usual, as long as physicians were dealing with a cluster of symptoms that had no name, there was no disease, while suggesting a name, even without any indication of causation, conferred a new credibility on the pathological condition. Today PPS is generally accepted as a defined clinical entity and its prevalence has been reported to be between $20 \%$ and $85 \%$ of people who have had poliomyelitis. In Italy the number of polio survivors is estimated at between 70,000 and 80,000 and as a consequence the number of people potentially exposed to the risk of PPS is between 10,000 and 70,000 . This of course is creating a new sanitary emergency and many scientific societies and patients' associations have changed their name and social scope to include PPS in their field of activity.

\section{Concluding remarks}

The historical analysis of the presence of polio epidemics in Italy shows their formidable impact on medicine, public health, social attitudes and culture. This case study can illustrate the repercussion of an epidemic of a severe disease on individual and collective life, and at the same time the paths to the implementation of public health measures against it.

The polio outbreaks coincide with a complex political period. The particular social and demographic history of the country after its unification in 1861 actually compressed the most dramatic history of the polio epidemic into only 40 years, from the first severe epidemic just before World War II to the second part of the 1970s, when the epidemic vanished thanks to an

53. Palmucci, Laura et al. Motor neuron disease following poliomyelitis. European Neurology. 1980; 19: 414-418; Schiffer, Davide et al. Mitochondrial abnormalities of late motor neuron degeneration following poliomyelitis and other neurogenic muscular atrophies. Journal of Neurology. 1979; 221: 193-201.

54. Halstead, Lauro S. Post-polio syndrome: definition of an elusive concept. In: Munsat, Theodore L., ed. Post-polio Syndrome. Boston: Butterworth-Heinemann; 1991, p. 23-28. 
effective and country-wide vaccination campaign. In the 1950s, fast moving socioeconomic factors, with rapid migration from rural to industrial areas, created a complex situation that brought about an unequal impact of the disease among the diverse areas of the country, as northern and southern parts were widely different in their socioeconomic status. The development of official and private measures ran parallel to the resurgence of the disease. The incorporation of previously isolated Italian researchers and clinicians to the study of polio at an international level culminated in the organization of the international polio conference held in Rome in 1954. The implementation of vaccination campaigns should be interpreted also in the context of the structure and dynamics of the Italian public health system and the exchange of experiences with other countries. The emergence of patients' associations and the movement for the rights of disabled people expanded and became influential, especially in favour of integration in the workplace and the fight against architectural barriers from the early 1960s onwards. 